\title{
BLEICH OU O PARADOXO DA TRADUÇÃO
}

\author{
Gilles Jean Abes \\ Universidade Federal de Santa Catarina \\ gillesabes@yahoo.fr
}

\begin{abstract}
Resumo: Este artigo tem por base um estudo comparativo das traduções de As flores do mal de Charles Baudelaire para o português principalmente, as de Jamil Almansur Haddad e de Ivan Junqueira. Centramo-nos inicialmente no poema $A$ cabeleira, tentando observar as posturas tradutórias que ora enobrecem, ora empobrecem a obra pelas "deformações" infringidas ao texto de partida sob o efeito de numerosas restrições. No texto literário, os rastros são particularmente visíveis, criando, assim, um lugar paradoxal para a tradução. Esse paradoxo ganha força ao debruçarmonos sobre a expressão "moeda falsa", que Carlos Drummond de Andrade empregou a respeito da tradução. Essa "condenação" surgiu da própria dificuldade do ato tradutório. Imbricam-se, assim, as moedas falsas do poeta brasileiro, de Derrida e de Baudelaire e, a partir dessa sentença, esse conceito desdobra-se em direções diversas: devemos entender essa "moeda falsa" enquanto singela falsificação? Constatamos esse fato, mas seria menosprezar a potência do texto traduzido encará-lo apenas sob essa forma. É na ótica da dissonância que é preciso abordar uma tradução. Dissonância sob forma de divergência que clama por outra tradução, fazendo dessa "peça falsa" uma máquina de provocar eventos.

Palavras-chave: tradução, Baudelaire, moeda falsa, dissonâncias.
\end{abstract}

\begin{abstract}
This article is based on a comparative study of Charles Baudelaire's Flowers of Evil (Les fleurs du mal) for the portuguese language, with special regard to Jamil Almansur Haddad and Ivan Junqueira's versions. At first, we focused on the poem Hair (La chevelure) trying to observe how the translator's approach can whether enrich or impoverish the work due to "deformations" imposed to the source text that come from several restrictions. In the literary text, those traces are particularly visible, creating a paradoxical setting for the translation. This paradox
\end{abstract}


becomes stronger as we look closely to the expression "counterfeit money" which Carlos Drummond de Andrade employed thinking through translation. This "conviction" emerged from the very difficulty of the translating process. Thus, all counterfeit currencies - Derrida, Baudelaire, and Drummond's, come together and, from that conviction, this concept unroll in several directions: should we understand this "counterfeit money" as a mere fraud? Considering this fact and this point of view, wouldn't we underestimate the power of the translated text? It is necessary to look at a translation and analyse it in terms of dissonance. Dissonance as a divergence asking for another translation, turning this "fake piece" into a machine which causes events.

Keywords: translation, Baudelaire, counterfeit money, dissonances.

Ainda às voltas com a tradução de Les Liaisons Dangereuses, de Laclos, trabalho que empreendi pelo suposto prazer de traduzir, sem encomenda

de editor. Que problema, escrever novamente um livro alheio! E que pretensão... Não sei o que mais padece neste jogo, se o pensamento do autor, se as palavras que o vestem. Para dizer a verdade, as traduções deviam ser proibidas, como moeda falsa. ${ }^{1}$

Como entender uma tal proibição? É certo que, frente à impossibilidade de um ato de traduzir satisfatório, a interdição brota da própria dificuldade perante as inúmeras escolhas e restrições impostas ao tradutor. No cerne da poesia, o tradutor encontra-se acorrentado a tantos elementos com os quais deve se deparar simultaneamente, que passa certamente por momentos de dúvida em prosseguir na sua empreitada. Como traduzir poesia levando em conta tantos fatores ao mesmo tempo como, por exemplo, sonoridade, rima, metro, sentido? - "Impossible!" urraria interiormente nossa intuição, segundo o filósofo Henri Bergson ${ }^{2}$. Mas nesse vazio deixado pela intraduzibilidade não nasceria um eco, "Impossible!... Impossible!... Impossible!...”, espelhando essa impossibilidade à impossibilidade, dando como resposta o impossível ao impossível, tornando, por sua vez, a tradução possível?

Berman nos lembra que "a intraduzibilidade é um dos modos de autoafirmação de um texto" ". Italo Calvino reforça ainda mais esse conceito ao afirmar em seu Por que ler os clássicos, que "um clássico é um livro que nunca acaba de dizer aquilo que tem para 
dizer" . Essa opacidade é própria a parte da linguagem literária moderna que surge no século XIX com poetas como Baudelaire e, particularmente, Rimbaud e Mallarmé. No entanto, historicamente, essa intraduzibilidade nem sempre foi aceita enquanto valor. Ao contrário, muitos eram os que viam nessas passagens "confusas" ou "pouco claras", um problema da ordem da retórica, que necessitava alteração. Não obstante, Jean Le Rond D’Alembert já defende, em sua época, o respeito à ambiguidade do autor a traduzir: "Tacite sous-entend beaucoup, et fait penser son lecteur; mérite qu'une traduction ne peut faire perdre" 5 . Essa citação do século XVIII não deixa de embasbacar, principalmente, ao comparar a situação atual do tradutor, ainda frequentemente invisível nas capas dos livros e, sobretudo, fazendo ele mesmo de sua tradução um texto que não aparenta ser traduzido - autoaniquilamento - que se priva, consciente ou incoscientemente, da letra, por exemplo. Essa privação tende a ser fruto de uma resistência do mercado livresco, dos leitores, ou da própria Academia, como afirma Victor Hugo:

Une traduction est presque toujours regardée tout d'abord par le peuple à qui on la donne comme une violence qu'on lui fait. Le goût bourgeois résiste à l'esprit universel.

Traduire un poète étranger, c'est accroître la poésie nationale; cet accroissement déplait à ceux auxquels il profite. C'est du moins le commencement; le premier mouvement étant la révolte. Une langue dans laquelle on transvase de la sorte un autre idiome fait ce qu'elle peut pour refuser. Elle en sera fortifiée plus tard, en attendant elle s'indigne. Cette saveur nouvelle lui répugne. Ces locutions insolites, ces tours inattendus, cette irruption sauvage de figures inconnues, tout cela, c'est de l'invasion. ${ }^{6}$

E a prática atual, ao menos em sua forte tendência, se apoia nessa revolta contra o inusitado, contra as culturas diversas ao país que acolhe a obra, para justificar a clarificação e, até mesmo, a deformação consciente dos tradutores. Havia ainda alguma esperança 
do tempo de Hugo, tempo em que o capitalismo nascente ainda não havia enleado totalmente suas garras no mercado livresco. No entanto, os folhetins apareceriam, sob o impulso de Girardin, assim como o mercantilismo, após a Revolução Industrial na Inglaterra, deixando pouco espaço às obras que "não vendem", como a poesia, por exemplo. O que será do tradutor nesse contexto? Terá novamente que escolher a quem se destinará sua obra. Assim, a respeito do puritanismo de Eduardo Lane, em sua tradução das Mil e uma noites, Borges afirma que uma razão para tal escolha "es que destinaba su obra 'a la mesita', centro de la lectura sin alarmas y de la recatada conversación" 7 . E essa escolha será de grande importância, já que "a tradução exerce um poder enorme na construção de representações de culturas estrangeiras" 8 .

Tendo esta vista estas considerações, tratemos de abordar as tendências deformadoras de traduções de alguns versos de Baudelaire. Uma das características da linguagem baudelairiana é a sua "simplicidade". Não obstante, é preciso não se ater em julgamentos precipitados, pois trata-se de uma escrita "simples" que, por um lado, nada tem a ver com o anódino, do ponto de vista literário e, por outro lado, é de uma complexidade subjacente, que jaz na criação/invenção dessa aparente "simplicidade" na conquista do efeito estético. Assim, para o tradutor, seria vital, em um primeiro momento, perceber essa característica, e, em um segundo momento, evitar o quanto possível a alteração desses versos "simples". Tomemos a primeira estrofe do poema "A cabeleira". Observa-se o quão delicada será a tradução do particípio presente "moutonnant", e constata-se igualmente a simplicidade do quarto e quinto versos: "Des souvenirs dormants dans cette chevelure, / Je la veux agiter dans l'air comme un mouchoir !". Ivan Junqueira conseguiu, em sua tradução, preservar essa falsa simplicidade dos versos, evitando assim a deformação, no sentido do enobrecimento, que no caso do estilo de Baudelaire, representaria certamente uma perda ou, ao menos, um afastamento. 
Ô toison, moutonnant jusque sur l'encolure !

A

Ô boucles! Ô parfum chargé de nonchaloir !

B

Extase! Pour peupler ce soir l'alcôve obscure

C

Des souvenirs dormants dans cette chevelure,

C

Je la veux agiter dans l'air comme un mouchoir !

B

Ó tosão que até a nuca encrespa-se em cachoeira! A

Ó cachos! Ó perfume que o ócio faz intenso!

B

Êxtase! Para encher à noite a alcova inteira

C

Das lembranças que dormem nessa cabeleira,

Quero agitá-la no ar como se agita um lenço! ${ }^{10}$

$\mathrm{C}$

B

No entanto, não o consegue sem algum sacrifício, não podendo manter o choque de palavras entre "l'alcôve" et "obscure" ("a alcova inteira"). Esse choque cria um efeito estético de grande valor, já que tem por resultado uma passagem ambígua que enriquece assim o poema. Na tradução de Jamil Almansur Haddad constata-se a mesma versão feita por Ivan Junqueira para o quinto verso; no entanto, o quarto verso é modificado para atender à rima do anterior no emprego da palavra "obscura", que foi privilegiada.

$\begin{array}{ll}\text { Ó tosão a ondular até a tua cintura! } & \text { A } \\ \text { Ó cachos! Ó perfume a que ócio está suspenso! } & \text { B } \\ \text { Êxtase! Por povoar à tarde a alcova obscura, } & \text { C } \\ \text { Da saudade que em tua cabeleira dura, } & \text { C } \\ \text { Quero agitá-la no ar como se agita um lenço! }{ }^{11} & \text { B }\end{array}$

Haddad valoriza assim o choque entre as palavras "alcova" e "obscura", que representam certamente uma janela fechada, onde o leitor poderá exercer sua imaginação, "reine des facultés", segundo Baudelaire. Não obstante, essa escolha teve por consequência, não somente um afastamento do sentido primeiro do quarto verso na língua de partida, com a intrusão da palavra "dura", mas, ainda, um curioso resultado se espelhados os termos “cabeleira/dura”. Há, 
nesse ponto, manifesto empobrecimento qualitativo da obra. Quanto à sua escolha para traduzir "moutonnant", o tradutor se explica em nota de rodapé, fornecendo, inclusive, outra opção possível: "Tosão a encarneirar-se até a tua cintura". Esta só não pôde se efetivar por uma questão de exigência métrica, segundo seus próprios comentários. A tradução de Pietro Nassetti ${ }^{12}$ é, ao mesmo tempo irrelevante e de forte interesse, já que modifica apenas uma palavra em comparação à de Haddad, trocando "suspenso" por "intenso". Assim, não contribui com nenhuma escolha diversa nos pontos críticos da tradução e motiva, ao mesmo tempo, uma discussão sobre a ética no bojo da tradução. Aliás, Ivo Barroso denunciou o saque a traduções de referência, inclusive de As flores do mal. Trata-se, nesse ponto, de uma nova tradução ou de um saque? Voltaremos a discutir a questão. Tomemos ainda a de Juremir Machado da Sil$\mathrm{va}^{13}$ para nova comparação, já que se trata de uma homenagem às traduções mais consagradas de As flores do $\mathrm{mal}^{14}$.

Ó vasta lã de carneiro ondulante até a cintura!

A

Ó cachos! Ó perfume cheio de volúpia e denso!

Êxtase! Para encher esta noite a alcova escura

B

Das lembranças dormindo na tua cabeleira pura,

Quero agitá-la no ar como se faz com um lenço!

A

B

A

A escolha do tradutor para o termo "moutonnant" não parece ser a mais feliz, já que se afasta da metáfora referente ao mar, à agua ou ao movimento das nuvens e causa grande impacto no ritmo do verso. No entanto, prefere a palavra "pura" à "dura", o que revela uma preocupação com uma tradução mais literal do terceiro verso. Outra escolha que deforma demasiadamente o poema é a do termo "encher" que substitui "povoar", mesma deformação encontrada em Ivan Junqueira. Há um empobrecimento qualitativo nesse ponto, tanto do ponto de vista estilístico como metafórico, já que "povoar a alcova obscura" nos parece comportar mais densidade poética. 
Constata-se nessas comparações a importância da tomada de decisão da parte do tradutor a partir de sua intimidade com o autor traduzido. Como afirma Jirí Levý, citado por Venuti,

a tradução é um PROCESSO DE DECISÕES: uma série de situações consecutivas - como jogadas em um jogo que impõem ao tradutor a necessidade de escolher entre um número determinado (e muitas vezes definível com exatidão) de alternativas. ${ }^{15}$

E, não se deve perder de vista outra problemática que enfrenta ao abordar a linguagem: "a dificuldad categórica de saber lo que pertence al poeta y lo que pertence al lenguaje" ${ }^{16}$. Pois não se trata de um simples instrumento, como lembra Roland Barthes em seu "Cours, entretiens et enquêtes" (1979):

Le langage n'est pas une sorte d'instrument d'appendice que l'homme aurait "en plus" pour lui permettre de communiquer avec son voisin, pour lui demander de lui passer le sel ou d'ouvrir la porte. Ce n'est pas du tout ça. En réalité, c'est le langage qui fait le sujet humain, l'homme n'existe pas en dehors du langage qui le constitue. ${ }^{17}$

Friedrich Schleiermacher já havia percebido e discutido, de forma surpreendente, essa dificuldade:

Acaso não precisamos muitas vezes traduzir o discurso de outro, que nos é completamente igual, apenas de outra mentalidade e temperamento? Quando sentimos que as mesmas palavras em nossa boca teriam um sentido completamente diferente ou ao menos um peso aqui mais forte, ali mais fraco que na sua, e que, se quiséssemos expressar o mesmo que ele, nós, segundo nosso modo, usaríamos palavras e expressões totalmente distintas, ao querermos definir mais 
precisamente este sentimento e ao tornar-se para nós pensamento, parece que traduzimos. Sim, às vezes, a nossos próprios discursos, depois de algum tempo, temos que traduzi-los se quisermos apropriarmo-nos novamente deles. ${ }^{18}$

Nas palavras de Drummond acima citadas: "Não sei o que mais padece neste jogo, se o pensamento do autor, se as palavras que o vestem".

Eis que ressurge aqui a comparação/definição que Drummond fez da tradução enquanto "moeda falsa". Mas antes de qualquer avanço riscoso nesse território, é preciso aclarar a questão negando a interpretação negativa do termo enquanto simples falsificação. Dito isso, voltemo-nos para a expressão do poeta mineiro, que não deixa de estabelecer relações perigosas com o estudo de Derrida ${ }^{19}$ a partir do poema em prosa, A moeda falsa de Charles Baudelaire. De fato, desta pesquisa irrompem ao menos duas interrogações: $\mathrm{O}$ que se entende por "moeda falsa"? O que advirá dessa "moeda falsa"? É preciso se questionar, assim como Derrida o faz, se há moeda, verdadeira, falsa, falsa verdadeira ou verdadeiramente falsa. Pois se a tradução é posta em paralelo com a "moeda falsa", não cessa de não dizê-lo. Como vimos, a invisibilidade do tradutor leva o leitor a crer em um texto escrito originalmente na língua de chegada. $\mathrm{O}$ texto romperia assim com sua ligação/relação com o de partida, fechando-se em uma chegada-chegada que aniquila virtualmente as marcas que levam à tradução e todo o esforço do tradutor que, por sua vez, se torna sombra de uma sombra, tradutor não explícito de uma não tradução: invisível. Isso se dá não somente pela pouca valorização do tradutor que ainda existe por parte de algumas editoras e pelo próprio autoaniquilamento, mas, igualmente, pelo rompimento dos rastros de uma alteridade: a letra, por exemplo. Isso resultaria de uma suposta expectativa de certo tipo de leitor, como foi visto anteriormente. Nesse fenômeno, a tradução devém um texto que é mastigado, ruminado, voltando em seu ponto de chegada e que não desvenda outro lugar que não seja essa chegada, dando assim a entender que nunca houve língua 
de partida. Não há mais partida, tampouco chegada: há um texto. Ao menos é o que potencialmente pode ocorrer aos leitores desatentos que não têm consciência desse processo de camuflagem ou que nada esperam de uma evidência da alteridade. Trata-se assim de uma falsa "moeda falsa". E isso significa também que já não há mais "moeda falsa" que poderia criar um meio para a explosão de inúmeras possibilidades. Culturalmente, o texto perderá parte do seu potencial para o leitor atento. Por outro lado, a tradução que se indentifica como tal, quer seja por razões comerciais ${ }^{20}$, pela filosofia das editoras ou pela conquista dos tradutores, tende, em sua condição de verdadeira "moeda falsa", a se tornar uma "máquina de provocar eventos" 21 . Esses eventos que Derrida aborda, o narrador do poema em prosa de Baudelaire La fausse monnaie os imagina, como pode se observar no trecho citado abaixo.

Mais dans mon misérable cerveau, toujours occupé à chercher midi à quatorze heures (de quelle fatigante faculté la nature m'a fait cadeau!), entre soudainement cette idée qu'une pareille conduite, de la part de mon ami, n'était excusable que par le désir de créer un événement dans la vie de ce pauvre diable, peut-être même de connaitre les conséquences diverses, funestes ou autres, que peut engendrer une pièce fausse dans la main d'un mendiant. $\mathrm{Ne}$ pouvait-elle pas se multiplier en pièces vraies ? Ne pouvait-elle pas aussi le conduire en prison ? Un cabaretier, un boulanger, par exemple, allait peut-être le faire arrêter comme faux-monnayeur ou comme propagateur de fausse monnaie. Tout aussi bien la pièce fausse serait peut-être, pour un pauvre petit spéculateur, le germe d'une richesse de quelques jours. Et ainsi ma fantaisie allait son train, prêtant des ailes à l'esprit de mon ami et tirant toutes les déductions possibles de toutes les hypothèses possibles. ${ }^{22}$

No entanto, em meu miserável cérebro, sempre ocupado em fazer de um argueiro um cavaleiro (com que exaustiva faculdade me brindou a natureza!), entrou súbito a ideia 
de que tal procedimento, da parte do meu amigo, só era desculpável pelo desejo de criar um acontecimento na vida daquele pobre-diabo, talvez até de conhecer as consequências diversas, funestas ou de outra espécie, que uma moeda falsa pode engendrar quando nas mãos de um mendigo. Não poderia ela multiplicar-se em moedas verdadeiras? não poderia, também, arrastá-lo à prisão? Talvez um taberneiro ou um padeiro, por exemplo, mandasse prendê-lo como fabricante ou passador de moeda falsa. Também poderia acontecer que a moeda falsa viesse a tornar-se, para um pobre, humilde especulador, o germe de uma riqueza de alguns dias. E assim a minha fantasia se espraiava, emprestando asas ao espírito do meu amigo e tirando todas as deduções possíveis de todas as hipóteses possíveis. ${ }^{23}$

Essa máquina de provocar eventos se dá pelo próprio lugar paradoxal da tradução. O termo/conceito bleich ${ }^{24}$ que etimologicamente significa "incolor" em saxão, teria dado origem, segundo Borges, a duas palavras aparentemente opostas: black (preto) e blanco (branco): curiosa tangência em que no ínfimo limiar germinam ausência e concentração de cores. A cor negra é a que absorve todos os raios luminosos, não refletindo nenhum e por isso aparecendo como desprovida de clareza. A cor branca é a que reflete todos os raios luminosos, não absorvendo nenhum e por isso aparecendo como clareza máxima. Dessa maneira, a luz é incolor e o preto, de certa forma, se equipara ao branco, já que também não possui cor. Assim, o bleich representaria esse espaço vazio, incolor, janela fechada em que a própria luz flerta com a ausência desta, em que a luz, para existir, precisa da sombra que produz. Curioso paradoxo etimológico que pode ser comparado ao da tradução, já que dessa zona de treva que a intraduzibilidade representa brota a traduzibilidade, dessa impossibilidade surge o possível. Eis um lugar, um espaço de trânsito onde os possíveis se fortalecem. Lugar que lembra o do termo khôra abordado por Derrida: "Sobre ela não se pode nem mesmo dizer que ela não é nem isto, nem aquilo, ou 
que é ao mesmo tempo isto e aquilo" 25 . E esse lugar "incolor" da tradução não pode senão valorizá-la, já que faz um apelo, produz um canto, como as sereias da Odisseia, que cativa o tradutor, que se lança em sua direção e se embate contra as rochas da insatisfação: insatisfações que pudemos observar nos versos de Baudelaire. Mas, novamente, eis que esse relativo fracasso da tradução clama por outra tradução, novo "fracasso" que necessita de uma resposta, uma nova versão que não poderá aproximar-se da perfeição e que não alumiará totalmente essa brecha deixada pela opaca linguagem e pelas escolhas do tradutor. Assim, a intraduzibilidade da linguagem poética lhe propicia um valor duplo, o da sua escuridão, que permite diversos aclaramentos, e, simultaneamente, o de luzes parciais e esparsas que produzem um verdadeiro apelo a outras traduções. O texto de partida se multiplica em diversas versões, que no seu conjunto, representariam as diferentes óticas e escolhas dos tradutores: em suas tentativas, desgraçadamente, enriquecem a poesia e a tradução. Resta a saber se esse "fracasso" pode ser nomeado da sorte, de maneira ubíqua, no cerne do ato de traduzir ou se pode se tratar, em casos esparsos, de uma "superstición" 26 como afirma Borges. Se a tradução da obra de Edgar Allan Poe por Charles Baudelaire é ou não melhor que o texto de partida, como se diz, nos parece irrelevante, já que seria preciso estipular sob quais critérios de valor tal indagação se apoia. De qualquer forma, a tradução do autor de As flores do mal foi fundamental, no sentido em que irradiou a obra do norte americano de Baltimore, pouco apreciado em sua terra natal. Eis um exemplo dessa paradoxal relação entre luz e sombra, em que uma não vive senão na oposição e na existência da outra e que "dá luz" a uma máquina de provocar eventos como disse Derrida.

Mas há ainda uma outra moeda, a "moeda falsa" verdadeiramente falsa. Nela, jaz o escândalo do roubo. A "moeda falsa" vista como singela falsificação. Eis o caso da editora Martin Claret que parece se destacar pelos vergonhosos plágios, buscando nas valiosas traduções de tempos atrás uma fonte de inspiração. Foi o caso 
de Modesto Carone, que ganhou sua ação contra a editora por ter reconhecido trechos inteiros de sua tradução de $O$ processo. Seria preciso examinar com cuidado as numerosas coincidências entre as traduções de As flores do mal por Haddad (1984) e Nassetti (2006), pois no trecho anteriormente citado, o tradutor da editora Martin Claret mudou apenas uma palavra em toda uma estrofe e essa mudança certamente não pode ser aceita como nova tradução. Examinando com mais atenção o poema $A$ cabeleira, percebe-se claramente a estratégia. Foram mudadas apenas 3 palavras e 2 versos (parcialmente) dos 35 versos repartidos em 7 estrofes, as 3 últimas sendo idênticas! Nem sequer o poema de abertura Ao leitor foi preservado das trocas, mutilações, inversões que em nada contribuem para uma nova tradução, tampouco para uma tradução nova no tempo (2006) e na linguagem, apenas talvez para as estantes. Outrossim, a relação entre a literatura e a moeda se encontra fortalecida nesses casos de plágio, se pensarmos no termo pièce (peça - em francês) enquanto moeda ${ }^{27}$, peça de teatro, de poema. É muito provável que nessa "moeda falsa" produzida sob a autoridade dessa editora, deve ter havido uma confusão entre a peça de literatura e a pièce da moeda que resultou em uma teatralização (no mau sentido) da tradução: verdadeira peça de teatro que finge ser contribuição científica. Restam duas questões: Qual é o limiar que efetiva o plágio? Pregaram-nos uma peça?

Finalmente, como último desdobramento da "moeda falsa", percebe-se etimologicamente que o vocábulo "falsa" tem por acepção menos anódina, o uso abusivo de dissonância em uma composição musical, composição que aliás pode novamente ser chamada de peça. Curiosamente, estas parecem imbricadas umas nas outras: peça de literatura (teatro, poesia), pièce de moeda e musical. É nessa ótica musical que relacionamos tradução e "moeda falsa": uma peça de literatura em que se constata uma dissonância, ou melhor, uma discordância que clama por justiça. Tratar-se-ia de uma divergência e não de uma falsificação, que faz com que o verdadeiro tradutor, com conhecimento sobre a obra do autor, com 
outro olhar e outras escolhas, defronte novamente o texto a ser traduzido.

\section{Notas}

1. ANDRADE, Carlos Drummond de. O observador no escritório. Rio de Janeiro: Record, 2006, p. 29. Comentário feito pelo autor, datado por ele mesmo no dia 26 de agosto de 1944. Drummond tem então 42 anos e já publicou, como poeta, Alguma poesia (1930), Brejo das almas (1934) e Sentimento do mundo (1940), e, como tradutor, Uma gota de veneno (1943), de François Mauriac.

2. BERGSON, Henri. La pensée et le mouvant: essais et conférences. Paris: Presses Universitaires de France, 1946, p. 119-120.

3. BERMAN, Antoine. A tradução e a letra ou o albergue longínquo: o intraduzível como valor. Tradução de Marie-Hélène Catherine Torres, Mauri Furlan, Andréia Guerini. Florianópolis: Nuplitt/Letras, 2006.

4. CALVINO, Italo. Por que ler os clássicos. São Paulo: Companhia das Letras, 1993.

5. D'ALEMBERT, Jean Le Rond. Observations sur l'art de traduire en général et sur cet essai de traduction en particulier (1759). p. 68. "Tacito subentende muito, e faz seu leitor pensar; mérito que uma tradução não pode perder." Trad. Lea Mara Valezi Staut. In: FAVERI, Cláudia Borges de; TORRES, Marie-Hélène Catherine (orgs.). Clássicos da teoria da tradução, v. 2 - francês-português. Florianópolis: UFSC, 2004.

6. Idem. HUGO, Victor. Prologue à la traduction des oeuvres de William Shakespeare par François-Victor Hugo (1865). p. 154. "Uma tradução é quase sempre considerada, pelo povo a quem é oferecida, como uma violência que se comete contra ele. O gosto burguês resiste ao espírito universal. Traduzir um poeta es- 
trangeiro é aumentar a poesia nacional; este acréscimo desagrada àqueles que dele tiram proveito. É, ao menos, o começo; o primeiro movimento é a revolta. Uma língua na qual se transvasa assim um outro idioma faz o que pode para recusar. Ela será fortalecida mais tarde, por enquanto ela se indigna. O sabor novo lhe repugna. As locuções insólitas, as maneiras inesperadas, a irrupção selvagem de figuras desconhecidas, tudo isso é invasão". Tradução de Pedro de Sousa.

7. BORGES, Jorge Luis. Los traductores de las 1001 noches. In: Historia de la eternidad. Buenos Aires: Viau y Zona, 1936.

8. VENUTI, Lawrence. A formação de identidades culturais. In: Escândalos da tradução. Bauru: EDUSC, 2002.

9. BAUDELAIRE, Charles. Oeuvres complètes. v. I et II. Paris: Gallimard, 1975-6, p. 26.

10. BAUDELAIRE, Charles. As flores do mal. In: Poesia e prosa. Edição organizada por Ivo Barroso. Trad. Ivan Junqueira. Rio de Janeiro: Nova Aguilar, 1995, p. 122.

11. BAUDELAIRE, Charles. As flores do mal. Tradução, introdução e notas de Jamil Almansur Haddad. São Paulo: Abril Cultural, 1984, p. 124.

12. BAUDELAIRE, Charles. As flores do mal. Trad. Pietro Nassetti. São Paulo: Martin Claret, 2006, p. 36.

13. BAUDELAIRE, Charles. Flores do mal: o amor segundo Charles Baudelaire. Trad. Juremir Machado da Silva. Porto Alegre: Sulina, 2003.

14. O tradutor se refere aqui às traduções de Jamil Almansur Haddad, Ivan Junqueira e Guilherme de Almeida.

15. VENUTI, Lawrence. A invisibilidade do tradutor. Trad. Carolina Alfaro. Rio de Janeiro: PUC-RJ, 1995. 
16. BORGES, Jorge Luis. Las versiones homéricas. In: Obras completas I. Madrid: Emecé, 1996, p. 239-243.

17. BARTHES, Roland. Oeuvres complètes, t 3: Cours, entretiens et enquêtes. Paris: Seuil, 1993, 062. “A linguagem não é um tipo de instrumento de apêndice que o homem teria 'a mais' para lhe permitir comunicar com seu vizinho, para pedir que lhe passe o sal, ou abra a porta. Não é isso. Na realidade, é a linguagem que faz o sujeito humano, o homem não existe fora da linguagem que o constitui; [...]" (trad. nossa).

18. SCHLEIERMACHER, Friedrich. Dos diferentes métodos de traduzir. Tradução de Mauri Furlan. Florianópolis: UFSC, 2007.

19. DERRIDA, Jacques. Donner le temps. 1. La fausse monnaie. Paris: Éditions Galilée, 1991.

20. O renome do tradutor sendo empregado neste caso como eficiente ferramenta de marketing. Observem os casos dos autores canônicos ou "populares" como Carlos Drummond de Andrade ou Mario Quintana ou de alguns poucos tradutores cujo nome já edificou uma força no cerne das universidades, livrarias, editoras e entre alguns leitores: Millôr Fernandes, Ivo Barroso, Ivan Junqueira ou Modesto Carone.

21. DERRIDA, Jacques. Donner le temps. 1. La fausse monnaie. Paris: Éditions Galilée, 1991, p. 125. "Ce texte est donc aussi la pièce, peut-être une pièce de fausse monnaie, à savoir une machine à provoquer des événements: [...]”.

22. BAUDELAIRE, Charles. Oeuvres complètes, v. I. La fausse monnaie. Paris: Gallimard, 1975-6, p. 324.

23. BAUdELAIRE, Charles. Pequenos poemas em prosa. In: BARROSO, Ivo (org.) Poesia e Prosa. Rio de Janeiro: Nova Aguilar, 1995, trad. Aurélio Buarque de Holanda Ferreira, p. 313.

24. Jorge Luis Borges fala de sua paixão por etimologia em uma entrevista concedida em Paris em abril de 1978 a Ramón Chão. Borges explica a origem da palavra blanco que viria do saxão bleich. O termo teria engendrado duas palavras 
vistas, de maneira trivial, como opostas: blanco e black. http://www.monde-diplomatique.fr/2001/08/CHAO/15501 acessado no dia 04/07/07 às 15h00.

25. DERRIDA, Jacques. Khôra. Trad. Nicia A. Bonatti. Campinas: Papirus, 1995, p. 10.

26. BORGES, Jorge Luis. Las versiones homéricas. In: Obras completas I. Madrid: Emecé, 1996, p. 239-243.

27. Uma moeda vista como pequena placa de de metal, geralmente circular, cunhada por autoridade soberana usada como meio de troca, de economia, ou como medida de valor (centavos, centimes d'euro etc.). 